\title{
Histopathological Variants of Hepatocellular Carcinomas: an Update Ac- cording to the 5th Edition of the WHO Classification of Digestive System Tumors
}

\author{
Haeryoung Kim 1 , Mi Jang ${ }^{2}$, Young Nyun Park ${ }^{2}$ \\ 'Department of Pathology, Seoul National University Hospital, Seoul National University College of Medicine, Seoul; 'Department of Pa- \\ thology, Brain Korea 21 PLUS Project for Medical Science, Yonsei University College of Medicine, Seoul, Korea
}

Received Jan. 8, 2020

Revised Feb. 11, 2020

Accepted Feb. 12, 2020
Hepatocellular carcinoma ( $\mathrm{HCC}$ ) is heterogeneous in pathogenesis, phenotype and biological behavior. Various histopathological features of HCC had been sporadically described, and with the identification of common molecular alterations of HCC and its genomic landscape over the last decade, morpho-molecular correlation of HCC has become possible. As a result, up to $35 \%$ of HCCs can now be classified into histopathological variants, many of which have unique molecular characteristics. This review will provide an introduction to the variously described histopathological variants of HCC in the updated WHO Classification of Digestive System Tumors. (J Liver Cancer 2020;20:17-24)

Keywords: Classification; Hepatocellular carcinoma; Pathology

\section{INTRODUCTION}

Hepatocellular carcinoma (HCC) is defined as a primary hepatic malignancy showing hepatocellular differentiation, and it accounts for $75-85 \%$ of primary liver cancers. ${ }^{1}$ HCCs mostly arise in a background of chronic liver disease, the most common etiologies being hepatitis B, hepatitis C, chronic alcohol abuse, non-alcoholic fatty liver disease, inherited diseases (e.g. hemochromatosis and glycogen storage disease), and exogenous substances, such as aflatoxin $\mathrm{B} 1 .^{1,2} \mathrm{~A}$ minority of HCCs develop in a background of normal or near-normal liver, the most common setting being HCCs arising in hepatocellular adenomas. ${ }^{1,3,4}$

\footnotetext{
Corresponding author : Young Nyun Park

Department of Pathology, Yonsei University College of Medicine, 50 Yonsei-ro, Seodaemun-gu, Seoul 03722, Korea

Tel. +82-2-2228-1678, Fax. +82-2-362-0860

E-mail; young0608@yuhs.ac

https://orcid.org/0000-0003-0357-7967
}

Histologically, conventional HCCs demonstrate hepatocytic differentiation (i.e., the tumor cells resemble the appearance of hepatocytes with varying degrees of cyto-architectural atypia). The typical HCC tumor cells are cuboidal in shape, contain abundant eosinophilic cytoplasm with centrally located nuclei, and are frequently arranged in a trabecular pattern of variable thickness that at least vaguely recapitulates the trabecular architecture of the normal hepatic acinus, with very little intratumoral stroma (Fig. 1). ${ }^{5}$ However, many cases demonstrate deviations from this pattern; for example, some HCCs are predominantly composed of tumor cells with clear cytoplasm, some may show a predominantly pseudoglandular architecture and some may show abundant intratumoral fibrous stroma.

The 4th Edition of the World Health Organization (WHO) Classification of Digestive System Tumors (2010) described the histopathological features of HCC in detail, including detailed descriptions of "cytological variants", such 
as pleomorphic cells, clear cells and spindle cells. ${ }^{6}$ In addition, a few "special types" of HCC were recognized, including fibrolamellar carcinoma, scirrhous HCC, undifferentiated carcinoma, lymphoepithelioma-like carcinoma and sarcomatoid HCC. At that time, these special types were based mostly on the morphological features of the tumor.

Since then, numerous large-scale genomic analyses in the recent years have clarified the mutational landscape and identified key cell-signaling and metabolic pathways related to hepatocarcinogenesis. ${ }^{7-10}$ This has resulted in a large number of molecular subclasses and signatures of HCC, and has highlighted the heterogeneity of HCC, in pathogenesis, phenotype and biological behavior. Recent studies have provided increasing evidence for morpho-molecular correlation of HCCs, and these efforts have resulted in several proposed histopathological variants of HCC. ${ }^{11}$ As many as 35\% of HCCs can now be classified into histopathological variants, which have been introduced in the latest WHO Classification of Digestive System Tumors, 5th Edition ${ }^{1}$ and the distinction between most of these variants is now supported by the molecular features of the tumors (Table 1). In this review, we will summarize the recently described histopathological variants of HCCs.
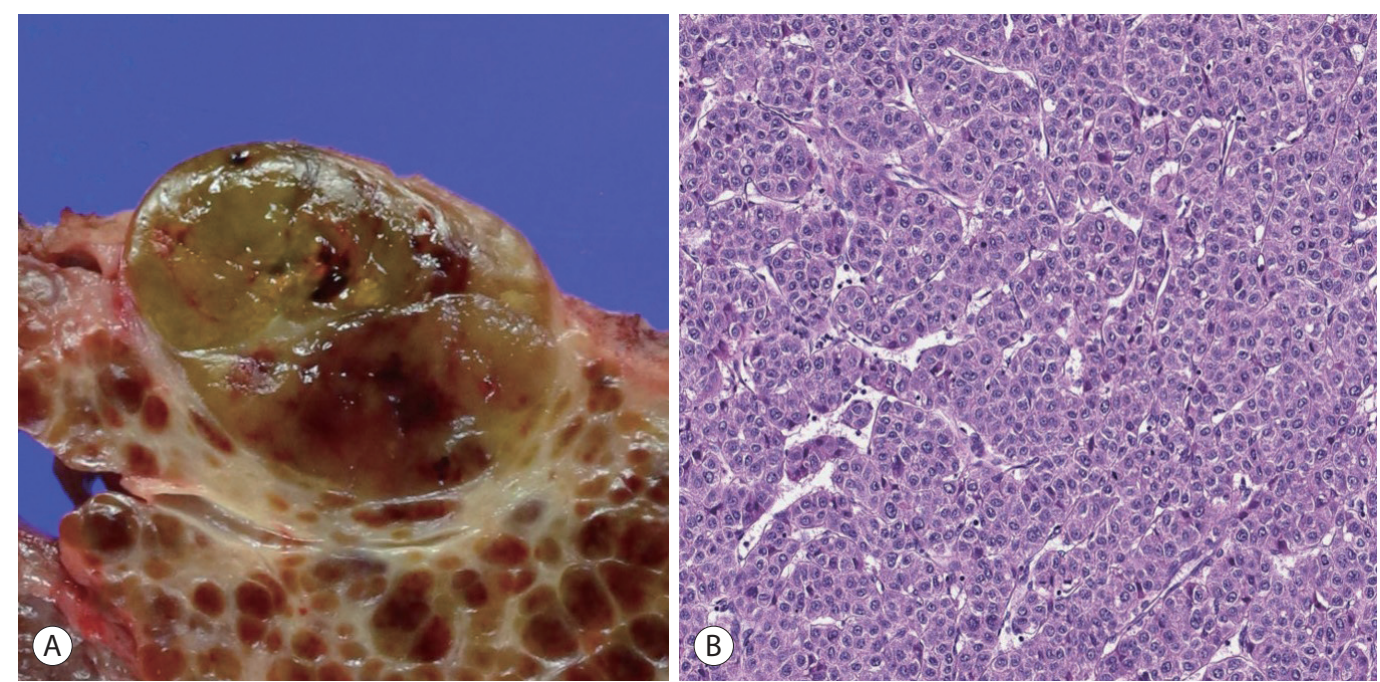

Figure 1. Hepatocellular carcinoma, conventional. (A) An expanding nodular tumor with a slightly bulging cut surface is seen. The tumor is slightly bile-tinged with small foci of hemorrhage. (B) Microscopic examination of a typical hepatocellular carcinoma shows tumor cells with eosinophilic cytoplasm arranged in a trabecular pattern (hematoxylin-eosin stain, $\times 200$ ).

\section{STEATOHEPATITIC VARIANT}

The steatohepatitic variant of HCC, or steatohepatitic HCC, demonstrates the histological features of steatohepatitis within the tumor, including steatosis, ballooning of tumor cells, inflammation and the typical "chicken-wire pattern" pericellular fibrosis (Fig. 2) ${ }^{11-14}$ It accounts for $5-20 \%$ of HCCs, and the background liver may show steatohepatitis. ${ }^{13,14}$ Although this variant has been shown to be less often associated with vascular invasion or satellite nodules, its prognosis seems to be similar to conventional HCCs so far. ${ }^{11}$ The key molecular features include IL-6/JAK/STAT activation, and lower frequency of CTNNB1, TERT, and TP53 mutations compared to other HCCs. ${ }^{11}$

\section{CLEAR CELL VARIANT}

In the clear cell variant of HCC, the majority $(>80 \%)$ of tumor cells demonstrate clear cytoplasm (Fig. 3). ${ }^{15}$ The clear cytoplasm is a result of glycogen accumulation, although it is sometimes hard to discriminate from lipid droplets that are intermixed; in this regard, some degree of steatosis is acceptable for a diagnosis of clear cell HCC. About 3-7\% of HCCs show this morphology, and although the prognosis has been 
shown to be better compared to conventional HCCs, there is still a lack of information on the clinical correlates or the molecular features of these tumors. Of note, it is important to discriminate clear cell HCC from metastatic clear cell renal cell carcinoma, as the morphology may be remarkably similar. Therefore, on encountering such cases in a biopsy, it is

Table 1. Summary of the clinical, histopathological and molecular features of the hepatocellular carcinoma variants according to the 5 th Edition of WHO Classification of Digestive System Tumors

\begin{tabular}{|c|c|c|c|}
\hline Variant & Histopathological features & Molecular features & Clinical features and prognosis \\
\hline Steatohepatitic & $\begin{array}{l}\text { Tumor cells show histological } \\
\text { features of steatohepatitis }\end{array}$ & $\begin{array}{l}\text { IL-6/JAK/STAT activation } \\
\text { Lower frequency of CTNNB1, } \\
\text { TERT and TP53 mutations }\end{array}$ & $\begin{array}{l}\text { NAFLD may be present } \\
\text { Prognosis similar to conventional HCC }\end{array}$ \\
\hline Clear cell & $\begin{array}{l}\text { Tumor cells show clear cytoplasm, } \\
\text { due to glycogen accumulation }\end{array}$ & Not known & $\begin{array}{l}\text { Better prognosis compared to conventional } \\
\text { HCC }\end{array}$ \\
\hline $\begin{array}{l}\text { Macrotrabecular- } \\
\text { massive }\end{array}$ & $\begin{array}{l}\text { Prominent thick trabeculae } \\
\text { (6-10 cells in thickness), frequent } \\
\text { vascular invasion }\end{array}$ & $\begin{array}{l}\text { Frequent TP53 mutation and } \\
\text { FGF19 amplification }\end{array}$ & Poor prognosis, high serum AFP levels \\
\hline Scirrhous & $\begin{array}{l}\text { Abundant intratumoral fibrous } \\
\text { stroma (30-50\% of the tumor), } \\
\text { frequent expression of stemness- } \\
\text { related markers }\end{array}$ & $\begin{array}{l}\text { Frequent TSC1/TSC } 2 \text { mutations, } \\
\text { TGF- } \beta \text { signaling activation }\end{array}$ & $\begin{array}{l}\text { Clinical outcome still controversial; larger } \\
\text { tumors have been associated with aggressive } \\
\text { outcome compared to conventional HCC } \\
\text { Imaging findings often overlap with } \\
\text { cholangiocarcinoma }\end{array}$ \\
\hline Chromophobe & $\begin{array}{l}\text { Clear cytoplasm, focal areas of } \\
\text { nuclear atypia (abrupt anaplasia) }\end{array}$ & ALT phenotype & Prognosis similar to conventional HCC \\
\hline Fibrolamellar HCC & $\begin{array}{l}\text { Large eosinophilic tumor cells } \\
\text { arranged in parallel arrays with } \\
\text { dense fibrous stroma }\end{array}$ & DNAJB1-PRKACA gene fusion & $\begin{array}{l}\text { Children and young adults; absence of } \\
\text { underlying chronic liver disease; more } \\
\text { frequent in Western countries } \\
\text { Better prognosis compared to conventional } \\
\text { HCCs in cirrhotic livers; similar prognosis to } \\
\text { HCCs in non-cirrhotic livers }\end{array}$ \\
\hline Neutrophil-rich & $\begin{array}{l}\text { Diffuse intratumoral neutrophilic } \\
\text { infiltration }\end{array}$ & G-CSF production by tumor & $\begin{array}{l}\text { Elevated blood leukocyte counts, C-reactive } \\
\text { protein and IL-6 } \\
\text { Poor prognosis compared to conventional HCC }\end{array}$ \\
\hline Lymphocyte-rich & $\begin{array}{l}\text { Massive intratumoral lymphocytic } \\
\text { infiltration, frequent PD-L1 } \\
\text { expression }\end{array}$ & Not known, not EBV-related & $\begin{array}{l}\text { Favorable clinical outcome compared to } \\
\text { conventional HCC }\end{array}$ \\
\hline
\end{tabular}

WHO, World Health Organization; IL, interleukin; JAK, janus kinase; STAT, signal transducer and activator of transcription; NAFLD, non-alcoholic fatty liver disease; HCC, hepatocellular carcinoma; AFP, alpha-fetoprotein; TGF- $\beta$, transforming growth factor-beta; ALT, alternative lengthening of telomere; G-CSF, granulocyte colony stimulating factor; PD-L1, programmed death-ligand 1; EBV, Epstein-Barr virus.
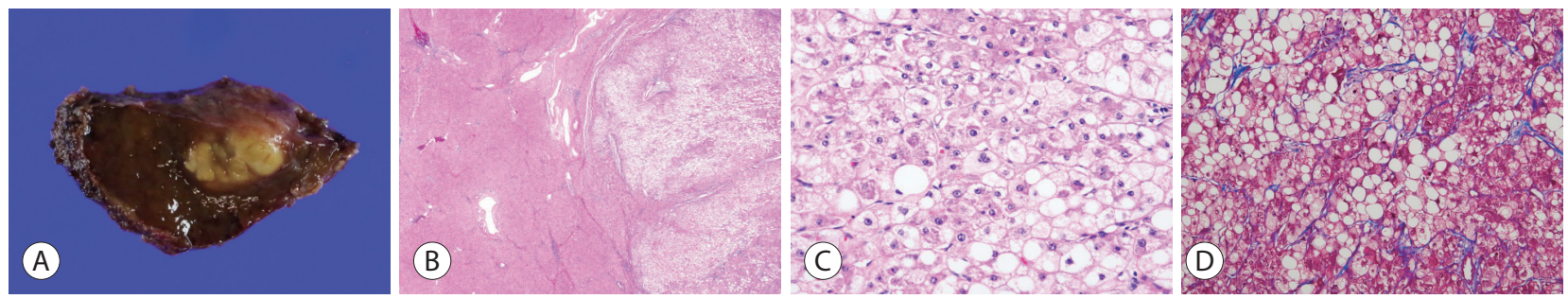

Figure 2. Hepatocellular carcinoma, steatohepatitic variant. (A) The tumor shows a yellowish hue on gross examination due to the lipid content. (B) At low power magnification, there is extensive intratumoral steatosis (right, hematoxylin-eosin stain, $\times 12.5)$. (C) Higher power magnification demonstrates the histological features of steatohepatitis, including steatosis, hepatocyte ballooning and Mallory-Denk bodies (hematoxylineosin stain, $\times 100)$. (D) The perisinusoidal "chicken-wire pattern" fibrosis is highlighted by Masson's trichrome stain $(\times 100)$. 
advisable to check the patient's clinicoradiological information, and to consider performing immunohistochemical stains (e.g., PAX-8, CD10, RCC for renal cell carcinoma, and hepatocellular differentiation markers such as HepPar-1 and arginase-1 for HCC) to avoid this diagnostic pitfall. ${ }^{16}$

\section{MACROTRABECULAR-MASSIVE VARIANT}

The macrotrabecular-massive variant of HCC demonstrates a characteristic microscopic appearance: prominent thick trabeculae, measuring more than 6-10 cells in thickness, in at least $50 \%$ of the tumor (Fig. 4). ${ }^{1,11,17}$ The relative
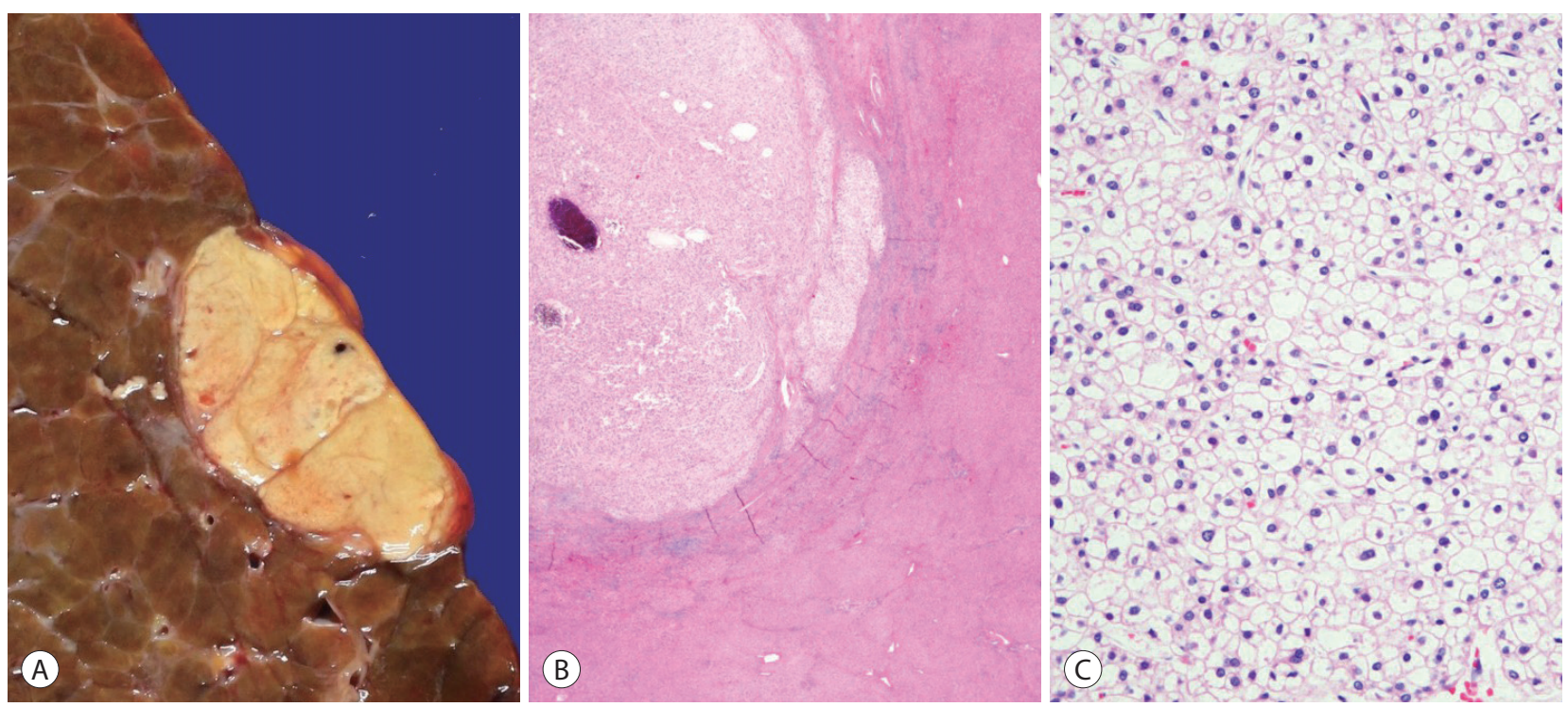

Figure 3. Hepatocellular carcinoma, clear cell variant. (A) Gross feature of the tumor. (B) The tumor (upper left) appears lighter compared to the adjacent hepatic parenchyma at low power (hematoxylin-eosin stain, $\times 12.5$ ). (C) Most of the tumor cells show clear cytoplasm, due to intracytoplasmic glycogen accumulation (hematoxylin-eosin stain, $\times 200$ ).
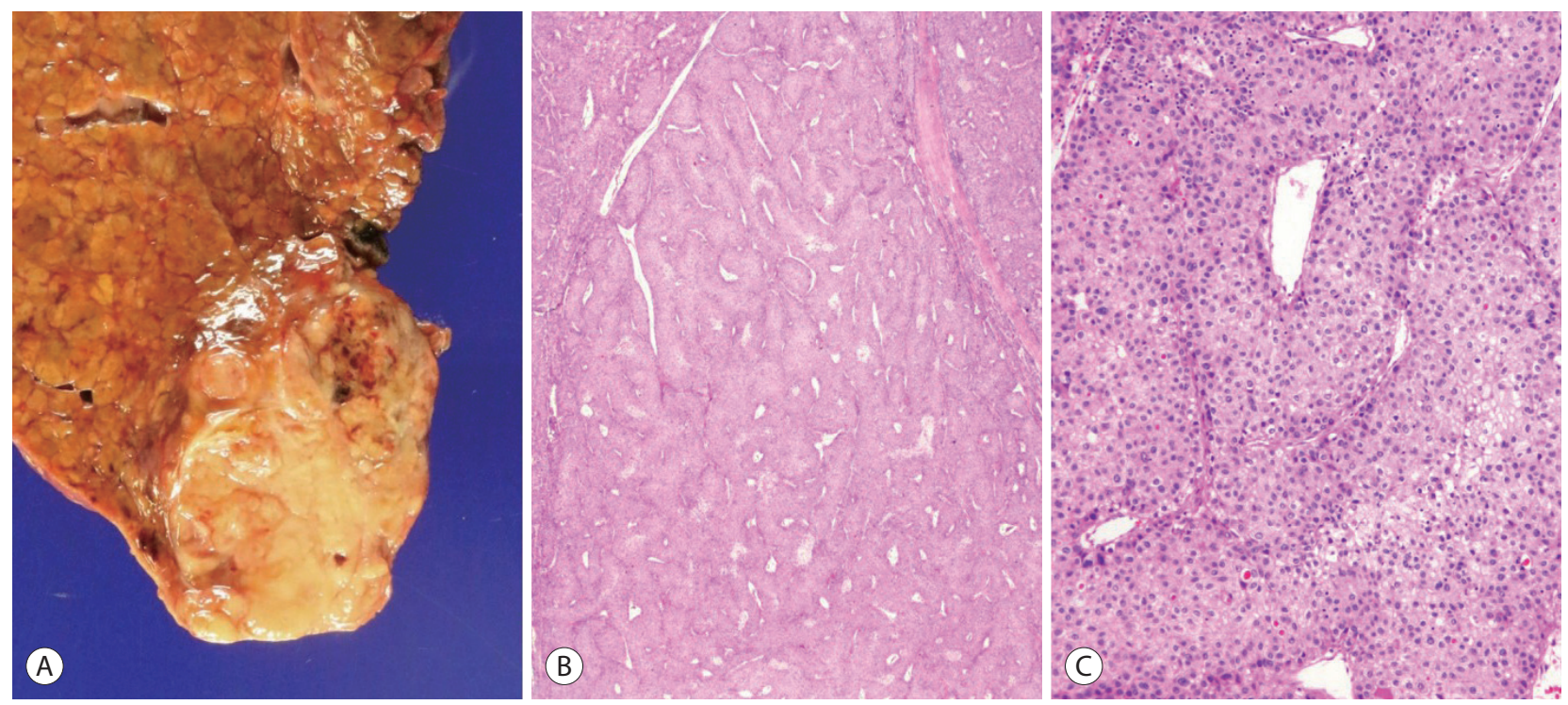

Figure 4. Hepatocellular carcinoma, macrotrabecular massive variant. (A) Gross feature of the tumor. (B) At low power magnification, thick tumor cell trabeculae are seen in more than $50 \%$ of the tumor (hematoxylin-eosin stain, $\times 12.5$ ). (C) The tumor cell trabeculae are more than 10 cells thick (hematoxylin-eosin stain, $\times 100$ ). 
frequency of this variant has been described to be about 5\% in the WHO classification, although some have reported frequencies of up to $20 \%$, probably as a result of the varying histological criteria; the trabecular thickness criteria for macrotrabecular-massive HCC has varied from 6 to 20 cells thick in the literature. From the molecular level, this variant is characterized by frequent TP53 mutation and FGF19 amplification. ${ }^{11,17}$ Macrotrabecular-massive HCCs have also been associated with frequent $\mathrm{HBV}$ infection, frequent vascular invasion, poor differentiation, CK19 expression, high serum AFP levels and a poor clinical outcome. ${ }^{11,17}$

\section{SCIRRHOUS VARIANT}

Scirrhous HCC is characterized by dense intratumoral fibrous stroma, occupying at least $30-50 \%$ of the tumor (Fig. 5). ${ }^{11,18-20}$ The tumor cell nests are predominantly composed of mature hepatocyte-like cells and rimmed by smaller tumor cells that resemble hepatic stem/progenitor cells - the latter population frequently express stemness-related markers, such as CK19, CK7, and epithelial cell adhesion molecule. ${ }^{19,20}$ This variant accounts for $4 \%$ of HCCs, and the dense fibrous stroma results in imaging findings that overlap with those of cholangiocarcinoma. TSC1/TSC2 mutations and transforming growth factor-beta signaling activation have been demonstrated in these tumors. ${ }^{11,20}$ The clinical outcome of this variant is still controversial. However, scirrhous HCCs have been reported to demonstrate decreased survival compared to conventional HCCs, especially in larger tumors ( $\geq 5 \mathrm{~cm}$ ), and aggressive pathological features (e.g. vascular invasion, infiltrative growth) have been more frequently seen in these tumors compared to conventional HCCs. ${ }^{20,21}$

\section{CHROMOPHOBE VARIANT}

This is a rare (up to 3\%) variant of HCC that is characterized by clear (chromophobic) cytoplasm of the tumor cells, and focal areas of striking nuclear atypia in a background of otherwise "bland-looking" cytology, and thus have been initially named "chromophobe HCC with abrupt anaplasia". 22 From a molecular viewpoint, it is interesting that the majority of the reported cases demonstrated alternative lengthening of telomere phenotype by telomere fluorescence in situ hybridization (FISH). ${ }^{22}$ Little is known regarding the clinical correlates of this variant, and the prognosis so far seems to be similar to conventional HCCs.
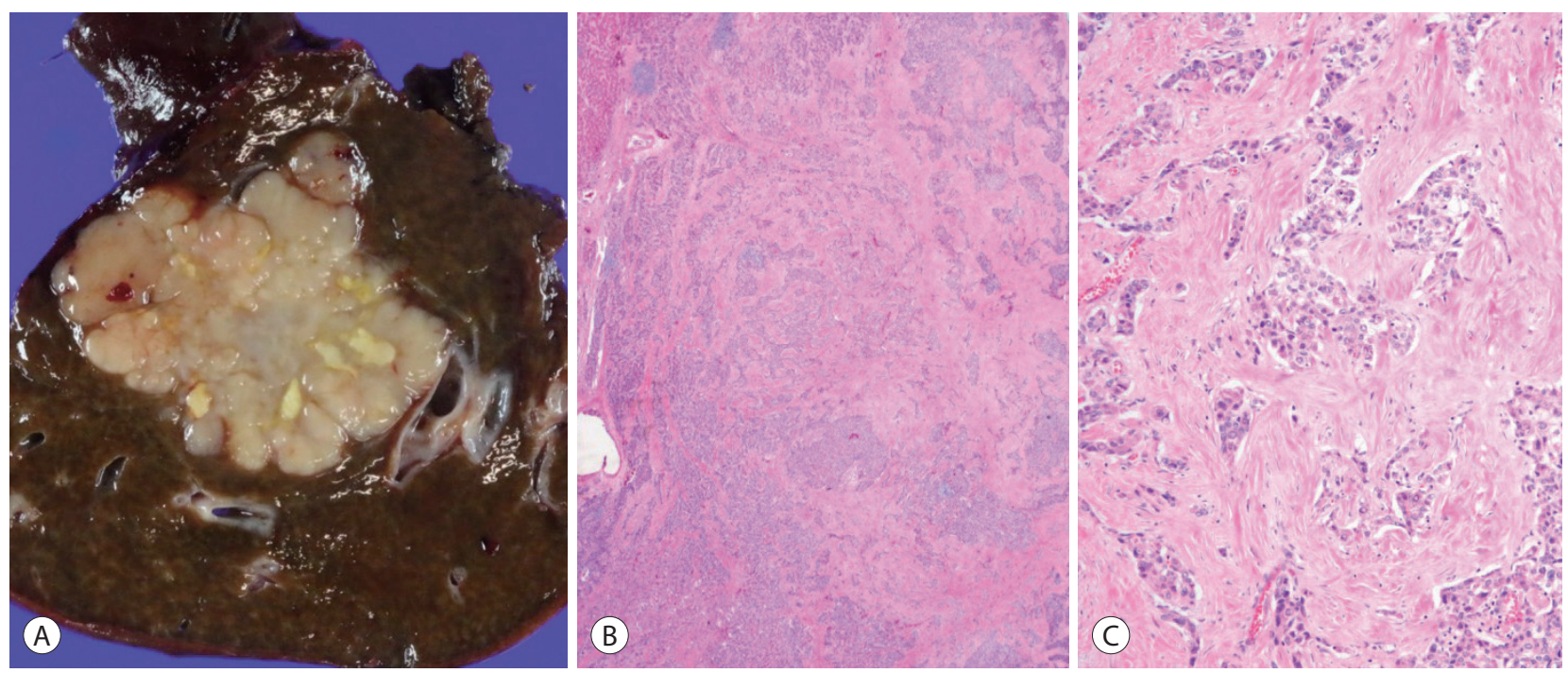

Figure 5. Hepatocellular carcinoma, scirrhous variant. (A) Gross feature of the tumor. (B) Dense intratumoral fibrosis is seen at low power magnification (hematoxylin-eosin stain, $\times 12.5$ ). (C) The tumor cell nests are separated by the thick fibrous stroma (hematoxylin-eosin stain, $\times 100$ ). 


\section{FIBROLAMELLAR HCC (FIBROLAMELLAR CARCINOMA)}

The fibrolamellar subtype of HCC had already been designated as a subtype of HCC in the previous WHO classification, ${ }^{6}$ and has unique clinical characteristics, including the age distribution (children and young adults) and the absence of underlying chronic liver disease. ${ }^{1,23}$ It is a rare subtype that accounts for up to $1 \%$ of HCCs and occurs more frequently in Western countries. ${ }^{1}$ Histologically, it is characterized by parallel arrays of large eosinophilic tumour cells with large vesicular nuclei and prominent nucleoli, and separated by dense fibrous septa. Due to the abundance of fibrous intratumoral stroma, it may appear similar to scirrhous HCC; however, the fibrous stroma of scirrhous HCC has been recently shown to contain more abundant cancer-associated fibroblasts and tumor-associated macrophages, and stemness-related marker expression is more frequently seen in scirrhous HCCs. ${ }^{24}$ Recently, DNAJB1-PRKACA gene fusion has been demonstrated in fibrolamellar HCC, and hence FISH for PRKACA gene rearrangement has been proposed to be a good diagnostic tool for this tumor. ${ }^{25,26}$ The prognosis of fibrolamellar HCC has been shown to be better than for con- ventional HCCs that arise in cirrhotic livers, but similar to HCCs in non-cirrhotic livers. ${ }^{27}$ In addition, conventional HCCs with features of fibrolamellar HCC in parts of the tumor have been shown to have similar prognosis with conventional HCCs, suggesting that a strict criterion (fibrolamellar features in the entire tumor) is required for a diagnosis of fibrolamellar HCC. ${ }^{28}$

\section{NEUTROPHIL-RICH VARIANT}

This is a very rare variant of HCCs (less than 1\%) that is characterized histologically by diffuse neutrophilic infiltration within the HCC, and clinically by elevated leukocyte counts, C-reactive protein and IL-6, and a poor prognosis compared to conventional HCCs. The tumor cells may have focal sarcomatoid appearance, and granulocyte colony-stimulating factor production by the tumor cells have been reported. $^{29}$

\section{LYMPHOCYTE-RICH VARIANT}

The lymphocyte-rich variant of HCC has been shown to account for $<1 \%$ of HCCs, and demonstrates massive intra-
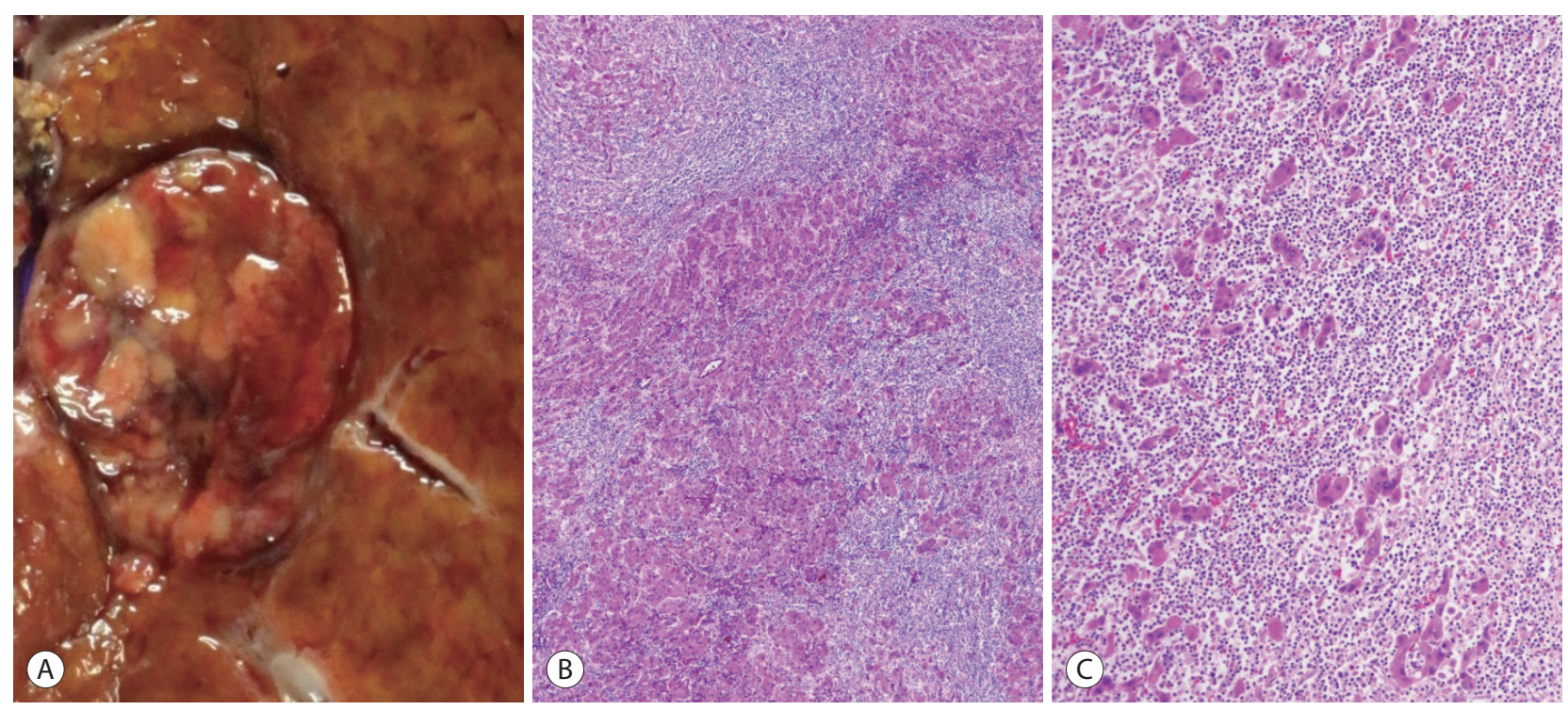

Figure 6. Hepatocellular carcinoma, lymphocyte-rich variant. (A) Gross appearance of the tumor. (B) At low power magnification, the tumor is massively infiltrated by lymphocytes (hematoxylin-eosin stain, $\times 40$ ). (C) The tumor cell trabeculae or nests are separated by dense lymphoid cell infiltrates (hematoxylin-eosin stain, $\times 100$ ). 
tumoral lymphocytic infiltration (Fig. 6). It has also been referred to as lymphoepithelioma-like HCCs. ${ }^{29,30}$ These tumors have been associated with a favorable clinical outcome and also more frequent programmed death-ligand 1 expression. ${ }^{31-33}$ The molecular features of this subtype have not been characterized yet; however, an association with EpsteinBarr virus infection has not been demonstrated, unlike similar tumors of some other organs such as the stomach. ${ }^{32}$ Interestingly, a minority of HCCs also demonstrates lymphoid aggregates or follicles within the tumor, and the presence of these tertiary lymphoid structures has been associated with a favorable prognosis. ${ }^{34}$

\section{CONCLUSION}

Following the accumulation of clinicopathological studies on various histopathological forms of HCC and the increasing number of molecular studies addressing the heterogeneity of HCC, there have been efforts to connect the histomorphological and molecular features of HCCs, and such links have resulted in the currently proposed HCC variants of the recent WHO Classification of Digestive System Tumors. ${ }^{1}$ With the recent morpho-molecular correlations of HCCs and the identification of various histopathological variants of HCC, most of which are based on their molecular features, we can now not only better understand the pathogenesis of HCC, but also use this knowledge to predict patient outcome and to facilitate the development of targeted therapy. More importantly, the identification of histopathological variants of HCCs suggests that histopathology still has an important role in HCC patient management.

\section{ACKNOWLEDGEMENTS}

This work was supported by the National Research Foundation of Korea (NRF) grant funded by the Korea government (MSIT) (NRF-2019R1A2C2010056, NRF-2016R1D1A1A09919042 to HK, NRF-2020R1A2B5B01001646, NRF-2017M3A9B6061512, and NRF-2016M3A9D5A01952416 to YNP).

\section{REFERENCES}

1. Torbenson MS, Ng IOL, Park YN, Roncalli M, Sakamoto M. Hepatocellular carcinoma. In: WHO Classification of Tumours Editorial Board, editor. Digestive system tumours. WHO classification of tumours series. 5th ed. Lyon: International Agency for Research on Cancer; 2019; 229-39.

2. Sanyal AJ, Yoon SK, Lencioni R. The etiology of hepatocellular carcinoma and consequences for treatment. Oncologist 2010;15 Suppl 4:14-22.

3. Degasperi E, Colombo M. Distinctive features of hepatocellular carcinoma in non-alcoholic fatty liver disease. Lancet Gastroenterol Hepatol 2016;1:156-164.

4. Nault JC, Mallet M, Pilati C, Calderaro J, Bioulac-Sage P, Laurent C, et al. High frequency of telomerase reverse-transcriptase promoter somatic mutations in hepatocellular carcinoma and preneoplastic lesions. Nat Commun 2013;4:2218.

5. Ferrell LD, Kakar $S$, Terracciano LM, Wee $A$. Tumours and tumourlike lesions of the liver. In: Burt AD, Ferrell LD, Hubscher SG, eds. MacSween's Pathology of the Liver, 7th ed. Philadelphia: Elsevier; 2018; 780-879.

6. Theise ND, Curado MP, Franceschi S, Hytiroglou P, Kudo M, Park YN, et al. Hepatocellular Carcinoma. In: Bosman FT, Carneiro F, Hruban RH, Theise ND, editors. WHO classification of tumours of the digestive system. 4th ed. Lyon: IARC; 2010; 205-16.

7. Hoshida Y, Nijman SM, Kobayashi M, Chan JA, Brunet JP, Chiang DY, et al. Integrative transcriptome analysis reveals common molecular subclasses of human hepatocellular carcinoma. Cancer Res 2009;69:7385-7392.

8. Boyault $S$, Rickman DS, de Reyniès $A$, Balabaud $C$, Rebouissou $S$, Jeannot $E$, et al. Transcriptome classification of HCC is related to gene alterations and to new therapeutic targets. Hepatology 2007:45:42-52.

9. Chiang DY, Villanueva A, Hoshida Y, Peix J, Newell P, Minguez B, et al. Focal gains of VEGFA and molecular classification of hepatocellular carcinoma. Cancer Res 2008;68:6779-6788.

10. Lee JS, Chu IS, Heo J, Calvisi DF, Sun Z, Roskams T, et al. Classification and prediction of survival in hepatocellular carcinoma by gene expression profiling. Hepatology 2004;40:667-676.

11. Calderaro J, Couchy G, Imbeaud S, Amaddeo G, Letouzé E, Blanc $J F$, et al. Histological subtypes of hepatocellular carcinoma are related to gene mutations and molecular tumour classification. J Hepatol 2017;67:727-738.

12. Lee JS, Yoo JE, Kim H, Rhee H, Koh MJ, Nahm JH, et al. Tumor stroma with senescence-associated secretory phenotype in steatohepatitic hepatocellular carcinoma. PLoS One 2017;12:e0171922.

13. Salomao $M$, Remotti $H$, Vaughan $R$, Siegel $A B$, Lefkowitch $J H$, Moreira RK. The steatohepatitic variant of hepatocellular carci- 
noma and its association with underlying steatohepatitis. Hum Pathol 2012;43:737-746.

14. Salomao M, Yu WM, Brown RS Jr, Emond JC, Lefkowitch JH. Steatohepatitic hepatocellular carcinoma (SH-HCC): a distinctive histological variant of HCC in hepatitis C virus-related cirrhosis with associated NAFLD/NASH. Am J Surg Pathol 2010;34:1630-1636.

15. Li T, Fan J, Qin LX, Zhou J, Sun HC, Qiu SJ, et al. Risk factors, prognosis, and management of early and late intrahepatic recurrence after resection of primary clear cell carcinoma of the liver. Ann Surg Oncol 2011;18:1955-1963.

16. Reuter VE, Argani P, Zhou M, Delahunt B; Members of the ISUP Immunohistochemistry in Diagnostic Urologic Pathology Group. Best practices recommendations in the application of immunohistochemistry in the kidney tumors: report from the International Society of Urologic Pathology consensus conference. Am J Surg Pathol 2014;38:e35-e49.

17. Ziol M, Poté N, Amaddeo G, Laurent A, Nault JC, Oberti F, et al. Macrotrabecular-massive hepatocellular carcinoma: a distinctive histological subtype with clinical relevance. Hepatology 2018;68:103-112.

18. Kurogi M, Nakashima O, Miyaaki H, Fujimoto M, Kojiro M. Clinicopathological study of scirrhous hepatocellular carcinoma. J Gastroenterol Hepatol 2006;21:1470-1477.

19. Matsuura S, Aishima S, Taguchi K, Asayama Y, Terashi T, Honda H, et al. 'Scirrhous' type hepatocellular carcinomas: a special reference to expression of cytokeratin 7 and hepatocyte paraffin 1. Histopathology 2005;47:382-390.

20. Seok JY, Na DC, Woo HG, Roncalli M, Kwon SM, Yoo JE, et al. A fibrous stromal component in hepatocellular carcinoma reveals a cholangiocarcinoma-like gene expression trait and epithelialmesenchymal transition. Hepatology 2012;55:1776-1786.

21. Kim SH, Lim HK, Lee WJ, Choi D, Park CK. Scirrhous hepatocellular carcinoma: comparison with usual hepatocellular carcinoma based on CT-pathologic features and long-term results after curative resection. Eur J Radiol 2009;69:123-130.

22. Wood LD, Heaphy CM, Daniel HD, Naini BV, Lassman CR, Arroyo $M R$, et al. Chromophobe hepatocellular carcinoma with abrupt anaplasia: a proposal for a new subtype of hepatocellular carcinoma with unique morphological and molecular features. Mod Pathol 2013;26:1586-1593.

23. Chagas AL, Kikuchi L, Herman P, Alencar RS, Tani CM, Diniz MA, et al. Clinical and pathological evaluation of fibrolamellar hepato- cellular carcinoma: a single center study of 21 cases. Clinics (Sao Paulo) 2015;70:207-213.

24. Kim YJ, Rhee H, Yoo JE, Alves VAF, Kim GJ, Kim HM, et al. Tumour epithelial and stromal characteristics of hepatocellular carcinomas with abundant fibrous stroma: fibrolamellar versus scirrhous hepatocellular carcinoma. Histopathology 2017;71:217-226.

25. Graham RP, Jin L, Knutson DL, Kloft-Nelson SM, Greipp PT, Waldburger $\mathrm{N}$, et al. DNAJB1-PRKACA is specific for fibrolamellar carcinoma. Mod Pathol 2015;28:822-829.

26. Honeyman JN, Simon EP, Robine N, Chiaroni-Clarke R, Darcy DG, Lim II, et al. Detection of a recurrent DNAJB1-PRKACA chimeric transcript in fibrolamellar hepatocellular carcinoma. Science 2014;343:1010-1014.

27. Kakar S, Burgart LJ, Batts KP, Garcia J, Jain D, Ferrell LD. Clinicopathologic features and survival in fibrolamellar carcinoma: comparison with conventional hepatocellular carcinoma with and without cirrhosis. Mod Pathol 2005;18:1417-1423.

28. Malouf GG, Brugières L, Le Deley MC, Faivre S, Fabre M, Paradis V, et al. Pure and mixed fibrolamellar hepatocellular carcinomas differ in natural history and prognosis after complete surgical resection. Cancer 2012;118:4981-4990.

29. Torbenson MS. Morphologic subtypes of hepatocellular carcinoma. Gastroenterol Clin North Am 2017;46:365-391.

30. Calderaro J, Ziol M, Paradis V, Zucman-Rossi J. Molecular and histological correlations in liver cancer. J Hepatol 2019;71:616-630.

31. Sia D, Jiao Y, Martinez-Quetglas I, Kuchuk O, Villacorta-Martin C, Castro de Moura M, et al. Identification of an immune-specific class of hepatocellular carcinoma, based on molecular features. Gastroenterology 2017;153:812-826.

32. Chan AW, Tong JH, Pan Y, Chan SL, Wong GL, Wong VW, et al. Lymphoepithelioma-like hepatocellular carcinoma: an uncommon variant of hepatocellular carcinoma with favorable outcome. Am J Surg Pathol 2015;39:304-312.

33. Calderaro J, Rousseau B, Amaddeo G, Mercey M, Charpy C, Costentin $C$, et al. Programmed death ligand 1 expression in hepatocellular carcinoma: relationship with clinical and pathological features. Hepatology 2016;64:2038-2046.

34. Calderaro J, Petitprez F, Becht E, Laurent A, Hirsch TZ, Rousseau $B$, et al. Intra-tumoral tertiary lymphoid structures are associated with a low risk of early recurrence of hepatocellular carcinoma. J Hepatol 2019;70:58-65. 